\title{
DETERMINAN YANG MEMPENGARUHI KINERJA KARYAWAN PADA BANK BRI CABANG KRAMAT JATI JAKARTA
}

\author{
Hepi Prayudiawan \\ UIN Syarif Hidayatullah Jakarta \\ hepi@uinjkt.ac.id
}

\begin{abstract}
.
There are a lot of factors that determine the employee performance, included competence, working disciplines, and working environment. The aim of this study is to determine the impact of competence, working disciplines, and working environment on Employee Performances in Bank of BRI, Kramat Jati Branch. The analysis method that used in this research is multiple regression. The result shows that the competence and working environment have a positive impact on employee performance. But, the working discipline don't has an impact on employee performance. There are several implication of this research, such as: first, the company should recruit the employee with good competency. Second, the company should create a conducive working environment. Third, the company should have a good regulation to make sure the working discipline.
\end{abstract}

Keywords: performance; competences; working disciplines; working environment.

\begin{abstract}
Abstrak.
Banyak faktor yang dapat mempengaruhi kinerja karyawan, diantaranya ialah kompetensi, disiplin kerja, dan lingkungan kerja. Tujuan dari kajian ini ialah untuk menentukan dampak kompetensi, disiplin kerja, dan lingkungan kerja terhadap kinerja karyawan pada Bank BRI Cabang Kramat Jati. Metode analisis yang dipergunakan ialah regresi berganda. Hasil yang ada menunjukkan bahwa kompetensi, dan lingkungan kerja memiliki dampak positif terhadap kinerja karyawan, sedangkan disiplin kerja tidak memiliki dampak terhadap kinerja karyawan. Terdapat beberapa implikasi dari kajian ini yaitu: pertama, perusahaan harus mencari karyawan yang memiliki kompetensi baik. Kedua, perusahaan harus menciptkan lingkungan kerja yang kondusif. Ketiga, perusahaan harus memiliki regulasi yang baik untuk memastikan disiplin kerja.
\end{abstract}

Kata Kunci: kinerja; kompetensi; disiplin kerja; lingkungan kerja.

Diterima: 23 Mei 2016; Direvisi: 12 Agustus 2016; Disetujui: 13 September 2016 


\section{PENDAHULUAN}

Setiap organisasi menginginkan untuk memiliki kinerja yang baik. Dengan kata lain apabila kinerja karyawan baik maka kemungkinan besar kinerja perusahaan juga baik. Menurut Mangkunegara (2011) bahwa kinerja yang baik dapat dilihat dari kualitas dan kuantitas hasil kerja yang dapat diselesaikan oleh seorang karyawan dalam melaksanakan tugas dan tanggung jawabnya. Apabila terjadi penurunan kinerja, maka harus diupayakan untuk mencari faktor penyebabnya, kemudian dicarikan pemecahan masalahnya agar tidak menjadi berlarut-larut yang nantinya dapat menghambat pencapaian tujuan.

Untuk meningkatkan kinerja karyawan perusahaan dapat menempuh beberapa cara misalnya meningkatkan kualitas, moral dan etos kerja karyawan, meningkatkan lingkungan kerja yang kondusif dan membangun sistem pengawasan yang efektif, meningkatkan kemampuan, keterampilan dan pengetahuan karyawan. Selain upaya-upaya diatas, tentunya kinerja karyawan dapat dipengaruhi oleh beberapa faktor seperti kompetensi karyawan, lingkungan kerja karyawan dan disiplin karyawan dalam bekerja.

Terbatasnya sumber daya manusia yang berkualitas menuntut perusahaan untuk memberikan berbagai macam pelatihan dan karyawan harus selalu menambah wawasan pengetahuan yang dimiliki untuk dapat bersaing di dalam pasar persaingan tenaga kerja (Fadli, dkk, 2012). Dalam hal ini antara perusahaan dan karyawan memiliki hubungan yang erat kaitannya dengan jalannya sebuah organisasi. Apabila perusahaan memiliki sumber daya manusia yang berkualitas maka akan berpengaruh terhadap kelangsungan hidup organisasi itu sendiri.

Selain kompetensi, faktor lain yang dapat mempengaruhi kinerja adalah disiplin kerja. Rivai dan Sagala (2010) mengatakan bahwa disiplin merupakan kesadaran dari seseorang untuk menaati sejumlah peraturan yang telah ditetapkan oleh perusahaan. Lingkungan kerja dapat mempengaruhi hasil kerja karyawan. Setiap karyawan tentunya menginginkan lingkungan dimana ia bekerja nyaman sehingga karyawan tidak terganggu dalam bekerja. Kenyamanan dalam bekerja akan berdampak pada kinerja karyawan. Dengan memberikan 
kenyamanan di lingkungan kerja, karyawan akan mampu melaksanakan pekerjaannya dengan baik, sehingga dapat tercapai hasil yang maksimal.

Untuk meningkatkan produktivitas karyawan yang diukur dari kinerjanya, perusahaan harus mempertimbangkan banyak faktor. Standar Kinerja merupakan tolak ukur seseorang dalam melaksanakan pekerjaannya. Agar memperoleh nilai tinggi, standar itu harus pula mempunyai nilai kompetitif, dalam arti bahwa dalam penerapannya harus dapat berfungsi sebagai alat pembanding anatara prestasi kerja seorang karyawan dengan karyawan lainnya yang melakukan pekerjaan yang sama (Veithzal dan Sagala, 2010). Penelitian ini berupaya untuk melakukan analisis terhadap pengaruh kompetensi, disiplin kerja, dan lingkungan kerja terhadap kinerja karyawan pada Bank BRI Cabang Kramat Jati.

\section{METODE}

Penelitian ini dilakukan pada Bank Rakyat Indonesia Cabang Jakarta Kramat Jati. Penelitian ini bertujuan untuk melihat dan menganalisa bagaimana pengaruh Kompetensi, Disiplin Kerja dan Lingkungan Kerja Terhadap Kinerja Karyawan, terutama tenaga Pemasaran yang menjadi tulang punggung BRI cabang Jakarta Kramat Jati dalam memperoleh pendapatannya. Populasi dalam penelitian ini adalah seluruh karyawan tenaga pemasaran dengan status karyawan tetap yang berada di BRI Cabang Jakarta Kramat Jati yang berjumlah 60 orang.

Teknik analisis yang dipergunakan dalam menentukan faktor yang mempengaruhi kinerja karyawan mempergunakan teknik analisis regresi berganda. Adapun persamaan matematisnya dapat dituliskan sebagai berikut:

Kin $=\alpha+\beta_{1}$ Komp $_{i}+\beta_{2}$ Disp $_{i}+\beta_{3}$ Lingk $_{i}+\varepsilon_{i}$

Dimana: Kin ialah kinerja karyawan; Komp ialah kompetensi karyawan; Disp ialah disiplin kerja karyawan; dan; Lingk ialah lingkungan kerja karyawan.

Adapun sebelum melakukan uji hipotesis perlu dilakukan uji validitas dan reliabilitas terhadap keabsahan kuesioner, sehingga kuesioner yang dipergunakan dapat dipertanggungjawabkan secara ilmiah. Uji validitas didefinisikan sebagai ukuran seberapa cermat suatu alat ukur melakukan fungsi ukurnya. Suatu instrument (Kuesioner) dikatakan reliabel jika jawaban seseorang terhadap pertanyaan adalah konsisten atau stabil dari waktu (Ghozali, 2013). Selain itu akan 
dilakukan pula pengujian asumsi klasik yang meliputi: uji multikoliniearitas, uji autokorelasi, dan uji heterokedastisitas.

\section{HASIL DAN PEMBAHASAN}

Hasil pengujian validitas yang dilakukan menunjukkan bahwa semua item pertanyaan yang diajukan dalam kuesioner valid. Hal ini menunjukkan bahwa kuesioner tersebut sudah sah dipergunakan dalam penelitian ini. Selain itu hasil pengujian reliabilitas menunjukkan bahwa seluruh item pertanyaan reliabel untuk dipergunakan dalam penelitian ini. Hasil uji asumsi klasik yang meliputi uji multikoliniearitas, uji heterokedastisitas, dan uji autokorelasi menunjukan bahwa penelitian ini terbebas dari penyakit asumsi klasik.

Tabel 1. Hasil Uji t

\begin{tabular}{|c|c|c|c|c|}
\hline \multirow[t]{2}{*}{ Model } & \multicolumn{2}{|c|}{ Unstandadized Coefficients } & \multirow[t]{2}{*}{$\mathbf{t}$} & \multirow[t]{2}{*}{ Sig } \\
\hline & B & Std Error & & \\
\hline Konstanta & 2.188 & 4.293 & 0.510 & 0.614 \\
\hline Kompetensi & 0.288 & 0.068 & 4.233 & 0.000 \\
\hline Disiplin & 0.044 & 0.061 & 0.728 & 0.471 \\
\hline Lingkungan & 0.356 & 0.107 & 3.339 & 0.002 \\
\hline
\end{tabular}

Sumber: Data Diolah

Berdasarkan hasil yang terdapat pada Tabel 1, menunjukkan bahwa hanya variabel kompetensi dan lingkungan kerja yang memiliki pengaruh terhadap kinerja karyawan, sedangkan variabel disiplin tidak berpengaruh terhadap kinerja karyawan. Nilai koefisien regresi variabel kompetensi sebesar 0.288 menunjukan bahwa setiap peningkatan kompetensi sebesar 1\% akan meningkatkan kinerja sebesar 28.8\% dengan asumsi variabel lain bernilai tetap. Selanjutnya, untuk variabel lingkungan kerja menunjukan koefesien regresi sebesar 0,356, hal ini memiliki arti bahwa apabila lingkungan kerja ditingkatkan 1\% maka variabel kinerja akan meningkat sebesar 35.6\% dengan asumsi variabel lain bernilai tetap. Selain itu hasil penelitian menunjukkan bahwa secara bersama-sama seluruh variabel bebas berpengaruh terhadap variabel terikat. Kemudian didapatkan pula nilai Adjusted R Square sebesar 0,710 atau 71\%. Hal ini berarti $71 \%$ variabel kinerja dipengaruhi oleh kompetensi, disiplin kerja dan lingkungan kerja, sedangkan sisanya sebesar 29\% dipengaruhi oleh variabel lain diluar dari model yang dipergunakan. 
Standar kinerja yang baik memiliki kriteria, yaitu (Sedarmayanti, 2011): (1) Dapat dicapai: sesuai dengan usaha yang dilakukan pada kondisi yang diharapkan. (2) Ekonomis: biaya rendah/wajar, dikaitkan dengan kegiatan yang dicakup. (3) Dapat diterapkan: sesuai kondisi yang ada. Jika terjadi perubahan kondisi, harus dibangun standar yang setiap saat disesuaikan dengan kondisi yang ada. (4) Konsisten: akan membantu keseragaman komunikasi dan operasi keseluruhan fungsi organisasi. (5) Menyeluruh: mencakup semua aktivitas yang saling berkaitan. (6) Dapat dimengerti: diekspresikan dengan mudah, jelas untuk menghindari kesalahan komuniasi/kekaburan, instruksi yang digunakan harus spesifik dan lengkap. (7) Dapat diukur: harus dapat dikomunikasikan dengan presisi. (8) Stabil: harus memiliki jangka waktu cukup untuk memprediksi dan menyediakan usaha yang akan dilakukan. (9) Dapat diadaptasi: harus didesain sehingga elemen dapat ditambah, dirubah, dan dibuat terkini tanpa melakukan perubahan pada seluruh struktur. (10) Legitimasi: secara resmi disetujui. (11) Seimbang: diterima sebagai dasar perbandingan oleh yang berkaitan dengan aktivitas yang dilakukan. (12) Fokus pada pelanggan: harus terarah pada hal penting yang diinginkan pelanggan (internal dan ekstrenal) seperti: siklus waktu, mutu, kinerja, jadwal, biaya, dan kepuasan pelanggan.

Hasil penelitian ini serupa dengan yang ditemukan oleh Pattiasina, dkk (2016) dimana terdapat pengaruh yang signifikan antara kompetensi sumber daya manusia dengan kinerja karyawan. Winanti (2011) menemukan pula bahwa kompetensi yang meliputi: kompetensi intelektual, emosional dan sosial memiliki pengaruh yang positif terhadap kinerja karyawan. Yunus (2012) menemukan bahwa kompetensi (kemampuan komunikasi, kerjasama, kepemimpinan, dan pemutusan pendapat) berpengaruh terhadap kinerja karyawan.

Menurut Darsono dan Siswandoko (2011), untuk mengetahui kompetensi pekerja harus diadakan ukuran penilaian, yang lazim disebut dengan standar kompetensi. standar itu meliputi: (a) Karakter individu, karakter atau watak, atau kepribadian merupakan faktor internal kompetensi. Karakter berpikir rasional, bertindak cermat, cepat, akurat, jujur dan bersedia bekerjasama merupakan dasar untuk menilai kompetensi seseorang. (b) Tugas kerja, tugas kerja yang sulit dan menantang, dan bisa diselesaikan cepat, tepat, dan akurat merupakan ukuran 
penilaian kompetensi seseorang. (c) Kinerja individu, kinerja yang di atas rata-rata orang lain yang selevel merupkan penilaian kompetensi seseorang. (d) Kriteria penilaian, harus objektif dan jujur, dan tidak memihak.

Hasil penelitian ini terkait disiplin kerja dan kinerja serupa dengan penelitian yang dilakukan Setiawan (2013) dan Sumaki, dkk (2015), dimana disiplin kerja tidak berpengaruh terhadap kinerja karyawan. Hasil berbeda ditemukan oleh Patmarina dan Erisna (2012) yang menemukan bahwa disiplin kerja berpengaruh terhadap kinerja karyawan dan produktivitas karyawan. Mahardhika, dkk (2016) menemukan pula bahwa disiplin kerja berpengaruh positif terhadap kinerja karyawan. Perbedaan hasil yang didapat dapat dimungkinkan karena perbedaan kuesioner yang dipergunakan.

Keith Davis dalam Mangkunegara (2004), faktor yang mempengaruhi disiplin kerja adalah sebagai berikut: (a) Jam Kerja; (b) Izin Karyawan; (c) Absensi Karyawan. Hasibuan (2000) mengatakan bahwa pada dasarnya banyak indikator yang mempengaruhi tingkat kedisiplinan karyawan di suatu organisasi, diantaranya: (a) Tujuan dan Kemampuan; (b) Teladan dan Pimpinan; (c) Balas Jasa; (d) Keadilan; (e) Pengawasan melekat; (f) Sanksi hukuman; (g) Ketegasan; (h) Hubungan Kemanusiaan.

Sofyan (2013) menemukan hasil yang serupa dengan penelitian ini, dimana terdapat pengaruh lingkungan kerja terhadap kinerja pegawai. Dewi dan Frianto menemukan hasil yang serupa pula dimana lingkungan kerja memiliki pengaruh yang positif terhadap kinerja karyawan dan motivasi. Cintia dan Gilang (2016) menemukan bahwa 44.9\% lingkungan kerja fisik dan 42.8\% lingkungan kerja non fisik berpengaruh terhadap kinerja karyawan.

Hasil penelitian ini menunjukkan bahwa lingkungan kerja dalam suatu perusahaan perlu diperhatikan, hal ini disebabkan karena lingkungan kerja mempunyai pengaruh langsung terhadap para karyawan. Lingkungan kerja yang kondusif dapat meningkatkan kinerja karyawan dan sebaliknya, lingkungan kerja yang tidak memadai akan dapat menurunkan kinerja karyawan. Kondisi lingkungan kerja dikatakan baik apabila manusia dapat melaksanakan kegiatan secara optimal, sehat, aman dan nyaman. Kesesuaian lingkungan kerja dapat dilihat akibatnya dalam jangka waktu yang lama. Lingkungan kerja yang kurang 
baik dapat menuntut tenaga kerja dan waktu yang lebih banyak dan tidak mendukung diperolehnya rancangan sistem kerja yang efisien.

\section{SIMPULAN}

Penelitian ini menunjukkan bahwa hanya variabel kompetensi karyawan dan lingkungan kerja yang berpengaruh terhadap kinerja karyawan, sedangkan disiplin kerja tidak berpengaruh terhadap kinerja. Implikasi dari hasil penelitian ini antara lain: pertama, merekrut karyawan yang memiliki kompetensi baik. Kedua, perusahaan harus menciptakan lingkungan kerja yang kondusif baik lingkungan fisik maupun non-fisik. Ketiga, perusahaan harus menciptakan aturan yang baku agar meningkatkan disiplin kerja.

\section{PUSTAKA ACUAN}

Cintia, E. \& A. Gilang. (2016). Pengaruh Lingkungan Kerja Fisik dan Non Fisik Terhadap Kinerja Karyawan Pada KPPN Bandung I. Jurnal Sosioteknologi. Vol. 15 (1): 136-154.

Darsono. P \& T. Siswandoko. (2011). Manajemen Sumber Daya Manusia Abad 21. Jakarta: Nusantara Consulting.

Dewi, S.K. \& A. Frianto. (2013). Pengaruh Lingkungan Kerja Terhadap Kinerja Karyawan Melalui Motivasi. Jurnal Ilmiah Manajemen. Vol. 1 (4): 10551065.

Ghozali, I. (2013). Aplikasi Analisis Multivariate Dengan Program SPSS. Semarang: Badan Penerbit Undip.

Hasibuan, M.S.P. (2012). Manajemen Sumber Daya Manusia. Jakarta: Bumi Aksara. Mahardika, P.A.C., dkk (2016). Pengaruh Kompensasi dan Disiplin Kerja Terhadap Kinerja Karyawan Pada Hotel Puri Bagus Lovina. E-Journal Bisma Universitas Pendidikan Ganesha. Vol. 4: 1-9.

Mangkunegara, A.P. (2011). Manajemen Sumber Daya Manusia Perusahaan. Jakarta: Remaja Rosdakarya.

Moeheriono. (2012). Pengukuran Kinerja Berbasis Kompetensi. Jakarta: Rajagrafindo Persada. 
Patmarina, H. \& N. Erisna. (2012). Pengaruh Disiplin Kerja Terhadap Kinerja Karyawan Yang Dimediasi Oleh Produktivitas Kerja Perusahaan CV Laut Selatan Jaya di Bandar Lampung. Jurnal Manajemen dan Bisnis. Vol. 3 No. 1: 19-37.

Pattiasina, M. dkk. (2016). Pengaruh Kompetensi Sumber Daya Manusia Terhadap Kinerja Karyawan PT Bank Tabungan Negara, Tbk, Kantor Cabang Manado. Jurnal Administrasi Bisnis. Vol. 4 (1): 1-6

Sedarmayanti. (2011). Manajemen Sumber Daya Manusia, Reformasi Birokrasi dan Manajemen Pegawai Negeri Sipil. Bandung: Refika Aditama.

Setiawan, A. (2013). Pengaruh Disiplin Kerja dan Motivasi Terhadap Kinerja Karyawan Pada Rumah Sakit Umum Daerah Kanjuruhan Malang. Jurnal Ilmu Manajemen. Vol. 1 (4): 1245-1253.

Siagian, S.P. (2012). Manajemen Sumber Daya Manusia. Jakarta: Bumi Aksara.

Sofyan, D.K. (2013). Pengaruh Lingkungan Kerja Terhadap Kinerja Kerja Pegawai BAPPEDA. Malikussaleh Industrial Engineering Journal. Vol. 2 (1): 18-23.

Sumaki, W.J. dkk. (2015). Pengaruh Disiplin Kerja, Budaya Organisasi dan Komunikasi Terhadap Kinerja Karyawan PT PLN (Persero) Wilayah Suluttenggo Area Manado. Jurnal Berkala Ilmiah Efisiensi. Vol. 15 (5): 538549.

Veithzal, R. \& J. Sagala. (2010). Manajemen Sumber Daya Manusia untuk Perusahaan. Jakarta: Rajagrafindo Persada.

Yunus, E. (2012). Pengaruh Kompetensi Sumber Daya Manusia Terhadap Kinerja Pegawai KPPBC Tipe Madya Pabean Tanjung Perak Surabaya. Ekuitas: Jurnal Ekonomi dan Keuangan. Vol. 16 (3): 368-387.

Yusuf, B. (2015). Manajemen Sumber Daya Manusia di Lembaga Keuangan Syariah. Jakarta: Rajawali Pers.

Winanti, M.B. (2011). Pengaruh Kompetensi Terhadap Kinerja Karyawan: Survei Pada PT Frisian Flag Indonesia, Wilayah Jawa Barat. Majalah Ilmiah Unikom. Vol. 7 (2): 249-267. 